\title{
SLongwoods Review
}

Volume 2, Number $2 \cdot 2004$

\section{Guest Adversaria}

Dink and his colleagues have Provided us with an interesting window on "the missing" - Canadian nursing graduates who have traded in the cold weather and unstable job circumstances of various Canadian provinces, but mainly Ontario, for the warmth and welcoming climes of North Carolina. I was a dean of nursing through the 1990s when jobs for new graduates disappeared almost completely and they were left to scrounge out casual positions where they get them. I counselled many to get out because they deserved a better reception for their hard work, enthusiasm and dedication than what was available anywhere in Canada. Furthermore, they needed full-time jobs to repay loans incurred while acquiring the specific skills that they found were not wanted and they needed stable positions that would allow them to develop confidence in their practice skills and to hone their judgement. Many of them were the best of our graduates - the "cream of the crop."

I told our "precious" Canadian graduates to go to the United States (and directed many to North Carolina specifically because other Canadian graduates had reported how satisfied they were with their positions and the way they were treated, and how much they loved the weather and the green space) where they would be valued for their skills, where a condition of employment in most organizations was support to pursue advanced degrees, and where they could get interesting positions because the scope of nursing practice is not nearly as constrained as it is in Canada. I am an enthusiastic supporter of the healthcare systems in Canadian provinces, but I am also aware that nurses pay a significant price in limitations in roles because the Canada Health Act awards physicians the gate-keeper role to the system unless provinces choose to widen it, which none has done. One consequence of the lack of centralized payer in the American approach to healthcare is the opportunity for nurses to develop interesting and creative provider roles. Nurses are also able to develop contracts with private health insurers and with Medicare and Medicaid insurance schemes for reimbursement. And, of course, there is a perception that U.S. nurses are held in higher regard by the public and within the healthcare system than they are in Canada.

The brain drain of Canadians to the United States has been going on ever since the two countries organized themselves into countries. Probably it was a "brawn drain" originally as loggers from New Brunswick and Quebec left to pursue better paying and more reliable jobs in the textile and leather mills of New England. We know the original major players in organized nursing in the United States were almost all Canadians who had gone south for "training" as nurses because opportunities were better there. These Canadian nurses eventually rose to positions of leadership; for example, Isabel Hampton Robb, the first director of nursing and first superintendent of the school of nursing at Johns Hopkins Hospital and the major force in organizing nurses into what became the American Nurses Association. Interestingly, she joined Dr. William Osler, the first Medical Director of Johns Hopkins who was also Canadian.

Helen Mussallem (1964) reported on the number of Canadian nurses who migrated annually to the United States in the 1950s: 935 in 1952, 1042 in 1953 and between 1250 and 1500 each year from 1956-1960. We don't know if those nurses left for the same reasons as those who left in the 1990s; but it would be interesting to examine proportionate to the Canadian nursing population, the size of the annual migration over the intervening decades.

The Pink et al. paper teases us with information about Canadian nursing migrants but leaves most questions unanswered. Brain drain can reflect lack of opportunities at home or exceptional and unmatchable opportunities in the country that attracts the migrants. Access to a credible database provides opportunities to get access to nurses who can provide the answers. Hopefully, these investigators will pursue these questions among many others: Why are Canadian nurses leaving now? What are the opportunities that attract them? What are the elements of the positions they hold that are satisfying and would need to be replicated to bring them home? What role does the environment beyond nursing (weather, cost of living, local and national politics, personal safety) attract or repel them? How many seek entry level and how many emigrate to accept senior positions? And finally, how do we get them back?

\section{References}

Mussallem, H.K. 1964. A Path to Quality: A Plan for the Development of Nursing Education Programs within the General Education System of Canada. Ottawa: Canadian Nurses Association.

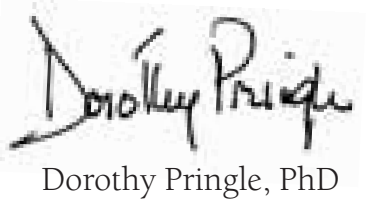

